\title{
Chronic Administration of Tadalafil Improves the Symptoms of Patients with Amicrobic MAGI: An Open Study
}

\author{
Sandro La Vignera, Rosita A. Condorelli, Laura M. Mongioi, and Aldo E. Calogero \\ Department of Clinical and Experimental Medicine, University of Catania, Catania, Italy \\ Correspondence should be addressed to Sandro La Vignera; sandrolavignera@unict.it
}

Received 30 December 2016; Revised 13 February 2017; Accepted 28 February 2017; Published 30 March 2017

Academic Editor: Małgorzata Kotula-Balak

Copyright (c) 2017 Sandro La Vignera et al. This is an open access article distributed under the Creative Commons Attribution License, which permits unrestricted use, distribution, and reproduction in any medium, provided the original work is properly cited.

\begin{abstract}
Aim of this study was to evaluate the effects of pharmacological treatment with Tadalafil $5 \mathrm{mg}$ daily on symptoms and quality of sperm parameters in selected patients with amicrobic MAGI (male accessory gland inflammation). 120 patients with amicrobic MAGI (mean age 27.0 \pm 6.0 years) with mild-moderate ED (erectile dysfunction) according to IIEF-5 (International Index of Erectile Function 5 Items) scores underwent pharmacological treatment with Tadalafil $5 \mathrm{mg}$ daily for six months. Before and after treatment these patients were evaluated through IIEF-5, semen analysis (according to WHO Criteria, 2010), SI-MAGI (Structured Interview about Male Accessory Gland Inflammation), and ultrasound evaluation. Patients with PVE (prostate-vesciculo-epididymitis) showed a significant increase in the percentage of spermatozoa with total (16.0 \pm 8.0 versus $30.0 \pm 6.0 \%)$ and progressive motility $(8.00 \pm 10.0$ versus $25.0 \pm 6.00 \%)$. It was a significant reduction of the number of patients with complicated ultrasound forms (30.0 versus 52.0) and a significant increase of the number of patients with uncomplicated ultrasound form (90.0 versus 68.0). Finally, there was a significant reduction in the percentage of patients with alterations of sexual function different from DE, such as premature ejaculation (4.00 versus $8.00 \%)$, painful ejaculation (4.00 versus $10.0 \%)$, delayed ejaculation (12.50 versus $8.00 \%$ ), and decreased libido (10.0 versus $25.0 \%$ ).
\end{abstract}

\section{Introduction}

The clinical presentation of patients with MAGI (male accessory gland inflammation) could be very heterogeneous; in fact, these patients may require andrological evaluation for problems (male infertility) $[1,2]$ and/or symptoms (chronic pelvic pain, ejaculatory and urinary disorders, and sexual dysfunction) [3]. Previously, we have shown that in the clinical practice, the use of a specific questionnaire [SI-MAGI (Structured Interview about Male Accessory Gland Inflammation)] helps to discriminate the differential diagnosis [4]. (Table 1 contains the questionnaire.)

Another very important aspect is the different anatomical extensions of the inflammation. From this point of view, MAGIs are classified into uncomplicated [P (prostatitis)] and complicated forms: PV (prostate-vesiculitis) and PVE (prostate-vesciculo-epididymitis). Generally, the complicated forms are associated with higher sperm abnormalities and increased severity of symptoms [4]. Moreover, the ultrasound evaluation represents an important tool for the differential diagnosis of complicated and uncomplicated forms [5]. ED (erectile dysfunction) and premature ejaculation represent the main sexual alterations in these patients [3]. This study assessed the changes observed after chronic daily treatment with Tadalafil (a specific inhibitor of $\mathrm{V}$ phosphodiesterase) regarding the symptoms and sperm parameters of the selected patients with MAGI.

\section{Materials and Methods}

One hundred twenty patients with amicrobic MAGI [1] were consecutively enrolled between 2013 and 2015, at the Institute of Andrology and Endocrinology of the University of Catania, Italy, aged between 20 and 45 years (mean age $27 \pm 6.0$ years) affected by mild-moderate ED, according to the scores obtained with IIEF-5 questionnaire (International Index of Erectile Function 5 Items) [6] administered during the first clinical evaluation. Table 2 shows the diagnostic criteria of MAGI. 
TABLE 1: Structured Interview about Male Accessory Gland Infections (SI-MAGI).

(a) Urinary disorders (levels of severity: absent: 0; mild: 1-6; moderate: 7-12; severe: 13-18)

\begin{tabular}{cccccc}
\hline & Question & 0 & 1 & 2 & 3 \\
\hline 1 & Nocturia & 0 times & 1 time & 2 times & $>2$ times \\
2 & Urinary frequency & Absent & Every 2 hours & $<2$ hours & Every 1 hour \\
3 & Strength of the urinary stream & Regular & Occasional difficulty & Constant difficulty & $\begin{array}{c}\text { Constant difficulty and } \\
\text { weakening voided urine }\end{array}$ \\
4 & Quality of urinary stream & Regular & With intervals & Irregular and continuous & Post micturition drip \\
5 & Failure to empty the bladder & Absent & Episodic & Frequent (>50\%) & Constant \\
6 & Duration of symptoms & Absent & $<1$ month & $1-3$ months & $>3$ months \\
\hline
\end{tabular}

(b) Spontaneous and/or ejaculatory pain or discomfort (levels of severity: absent: 0; mild: 1-8; moderate: 9-16; severe: 17-24)

\begin{tabular}{|c|c|c|c|c|c|}
\hline & Item & 0 & 1 & 2 & 3 \\
\hline 1 & Perineal area & Absent & $\begin{array}{l}\text { Occasional and/or } \\
<3 \text { months }\end{array}$ & $>50 \%$ or $>3$ months & $\begin{array}{l}\text { Constant and by more than } \\
3 \text { months }\end{array}$ \\
\hline 2 & Inguinal area & Absent & $\begin{array}{l}\text { Occasional and/or } \\
<3 \text { months }\end{array}$ & $>50 \%$ or $>3$ months & $\begin{array}{l}\text { Constant and by more than } \\
3 \text { months }\end{array}$ \\
\hline 3 & Scrotal area & Absent & $\begin{array}{l}\text { Occasional and/or } \\
<3 \text { months }\end{array}$ & $>50 \%$ or $>3$ months & $\begin{array}{l}\text { Constant and by more than } \\
3 \text { months }\end{array}$ \\
\hline 4 & Penile area & Absent & $\begin{array}{l}\text { Occasional and/or } \\
<3 \text { months }\end{array}$ & $>50 \%$ or $>3$ months & $\begin{array}{l}\text { Constant and by more than } \\
3 \text { months }\end{array}$ \\
\hline 5 & Coccyx area & Absent & $\begin{array}{l}\text { Occasional and/or } \\
<3 \text { months }\end{array}$ & $>50 \%$ or $>3$ months & $\begin{array}{l}\text { Constant and by more than } \\
3 \text { months }\end{array}$ \\
\hline 6 & Suprapubic area & Absent & $\begin{array}{l}\text { Occasional and/or } \\
<3 \text { months }\end{array}$ & $>50 \%$ or $>3$ months & $\begin{array}{l}\text { Constant and by more than } \\
3 \text { months }\end{array}$ \\
\hline 7 & $\begin{array}{l}\text { Irregular bowel and/or diarrhea } \\
\text { and/or hematochezia }\end{array}$ & Absent & $\begin{array}{c}\text { Presence of }<1 \text { symptom } \\
\text { and/or sign }\end{array}$ & Presence of 2 symptoms/signs & Presence of 3 symptoms/signs \\
\hline 8 & Duration of symptoms & Absent & $<1$ month & 1-3 months & $>3$ months \\
\hline
\end{tabular}

(c) Sexual function (levels of severity: absent: 0; mild: 1-11; moderate: 12-22; severe: 23-33)

\begin{tabular}{|c|c|c|c|c|c|}
\hline & Item & 0 & 1 & 2 & 3 \\
\hline 1 & Reduction of libido & Absent & Occasional and/or $>3$ months & $>50 \%$ and/or $>3$ months & Constant and/or $>3$ months \\
\hline 2 & $\begin{array}{l}\text { Erectile dysfunction } \\
\quad \text { (achievement) }\end{array}$ & Absent & Occasional and/or $>3$ months & $>50 \%$ and/or $>3$ months & Constant and/or $>3$ months \\
\hline 3 & $\begin{array}{l}\text { Erectile dysfunction } \\
\quad \text { (maintenance) }\end{array}$ & Absent & Occasional and/or $>3$ months & $>50 \%$ and/or $>3$ months & Constant and/or $>3$ months \\
\hline 4 & $\begin{array}{l}\text { Difficulties in the second } \\
\text { report }\end{array}$ & Absent & Occasional and/or $>3$ months & $>50 \%$ and/or $>3$ months & Constant and/or $>3$ months \\
\hline 5 & Premature ejaculation & Absent & Occasional and/or $>3$ months & $>50 \%$ and/or $>3$ months & Constant and/or $>3$ months \\
\hline 6 & Delayed ejaculation & Absent & Occasional and/or $>3$ months & $>50 \%$ and/or $>3$ months & Constant and/or $>3$ months \\
\hline 7 & $\begin{array}{l}\text { Alteration of the macro- } \\
\text { scopic character of the } \\
\text { ejaculate }\end{array}$ & Absent & $\begin{array}{l}\text { One of the following: stringy, } \\
\text { yellow or red-brown, volume } \\
\text { reduction }\end{array}$ & $\begin{array}{l}\text { Two of the following: stringy, } \\
\text { yellow or red-brown, volume } \\
\text { reduction }\end{array}$ & $\begin{array}{l}\text { All of the following: stringy, } \\
\text { yellow or red-brown, volume } \\
\text { reduction }\end{array}$ \\
\hline 8 & Painful ejaculation & Absent & Episodic & Frequent $(>50 \%)$ & Constant \\
\hline 9 & Ejaculate emission & Absent & Occasionally weakened & Weakened $>50 \%$ of the time & Increasingly weakened \\
\hline 10 & Prostatorrhea & Absent & Episodic & Frequent $(>50 \%)$ & Constant \\
\hline 11 & Hyperspermia & Absent & Episodic & Frequent $(>50 \%)$ & Constant \\
\hline
\end{tabular}


(d) Quality of life (levels of severity: absent: 0; mild: 1-5; moderate: 6-10; severe: 11-15)

\begin{tabular}{|c|c|c|c|c|c|}
\hline & Item & 0 & 1 & 2 & 3 \\
\hline 1 & $\begin{array}{l}\text { Quality of life associated with } \\
\text { the onset of symptoms }\end{array}$ & Like before & Satisfactions and failures & $\begin{array}{l}\text { Frustrating and/or } \\
\text { use of psychoanalysis }\end{array}$ & $\begin{array}{l}\text { Terrible with recourse to } \\
\text { psychoanalysis and/or drugs }\end{array}$ \\
\hline 2 & $\begin{array}{l}\text { Life changes associated with } \\
\text { the onset of symptoms }\end{array}$ & Absent & Few & Several & Several and important \\
\hline 3 & School or work days lost & 0 & 1 day per month & 2 days a month & $>2$ days per month \\
\hline 4 & $\begin{array}{c}\text { Quality of married life since it } \\
\text { began a diagnostic evaluation } \\
\text { and/or treatment }\end{array}$ & Like before & Satisfactions and failures & $\begin{array}{l}\text { Frustrating and/or use } \\
\text { of psychoanalysis }\end{array}$ & $\begin{array}{l}\text { Terrible with recourse to } \\
\text { psychoanalysis and/or drugs }\end{array}$ \\
\hline 5 & Infertility duration & $<1$ year & $1-2$ years & 3-4 years & $>4$ years \\
\hline
\end{tabular}

(e) Ultrasound criteria of MAGI

Prostatitis is suspected in the presence of $>2$ of the following ultrasonographic signs:

(1) asymmetry of the gland volume; (2) areas of low echogenicity; (3) areas of high echogenicity; (4) dilatation of periprostatic venous plexus; (5) single or multiple internal similar cystitis areas; and (6) area/s of moderate increased of vascularity (focal or multiple).

Vesiculitis is suspected in the presence of $>2$ of the following ultrasonographic signs:

(1) increase $(>14 \mathrm{~mm}$ ) anteroposterior diameter mono or bilateral; (2) asymmetry $>2.5 \mathrm{~mm}$ (normal 7-14 mm) compared to the contralateral vesicle; (3) reduced ( $<7 \mathrm{~mm}$ ) anteroposterior diameter mono or bilateral; (4) glandular epithelium thickened and/or calcified; (5) polycyclic areas separated by hyperechoic septa in one or both vesicles; (6) fundus/body ratio $>2.5$; (7) fundus/body ratio $<1$; and (8) anteroposterior diameter unchanged after recent immediately ejaculation.

Epididymitis is suspected in the presence of $>2$ of the following ultrasonographic signs:

(1) increase in size of the head (craniocaudal diameter $>12 \mathrm{~mm}$ ) and/or of the tail (craniocaudal diameter $>6 \mathrm{~mm}$ ) (finding single or bilateral); (2) presence of multiple microcystis in the head and/or tail (finding single or bilateral); (3) low echogenicity or high echogenicity mono or bilateral; (4) large hydrocele mono or bilateral; (5) enlargement in the superior part of the cephalic tract and the superior/inferior part ratio $>1$; and (6) unchanged anteroposterior diameter of tail after ejaculation.

Patients were classified into uncomplicated and complicated forms, according to the ultrasound examination performed at enrollment (Table 1 contains the ultrasound criteria previously published) [5].

All patients were subjected to the following diagnostic procedure:

(i) Administration of SI-MAGI questionnaire [4]

(ii) Sperm analysis after days of sexual abstinence [7]

(iii) Ultrasound evaluation of scrotal and prostatovesicular tract [5].

Diagnostic evaluation was performed at baseline and after six months of daily administration with Tadalafil $5 \mathrm{mg}$.

2.1. Exclusion Criteria. Endocrine and vascular alterations associated with ED (hypogonadism, hyperprolactinemia, obesity, diabetes mellitus, atherosclerosis, hypertension, and dyslipidemia). Patients with positive microbiological tests (semen culture, urine culture, HPV-DNA by PCR testing, and Stamey test).

The study was approved by the Internal Institutional Board, and all examined patients signed informed consent to the processing of personal data.

2.2. Statistical Analysis. Results are reported as mean \pm SEM throughout the study. The data were analyzed by 1-way
TABle 2: Diagnostic criteria of MAGI [1, 3-5, 19-21].

(a) History of urogenital infection and/or abnormal rectal palpation.

(b) Significant alterations in the expressed prostatic fluid and/or urinary sediment after prostatic massage.

(c) (1) Uniform growth of more than 10(3) pathogenic bacteria or more than 10(4) nonpathogenic bacteria per $\mathrm{ml}$, in a culture of diluted seminal plasma.

(c) (2) Presence of more than 10(6) (peroxidase positive) leucocytes per ml of ejaculate.

(c) (3) Signs of disturbed secretory function of the prostate or seminal vesicles.

Diagnosis is accepted if at least 2 criteria are present:
(i) $a+b$,
(ii) $\mathrm{a}+\mathrm{c}[1$ or 2 or 3$]$,
(iii) $\mathrm{b}+\mathrm{c}[1$ or 2 or 3$]$,
(iv) $\mathrm{c} 1+\mathrm{c} 2$,
(v) $\mathrm{cl}+\mathrm{c} 3$,
(vi) $\mathrm{c} 2+\mathrm{c} 3$.

analysis of variance (ANOVA) followed by Tukey's test, as appropriate. The software SPSS 22.0 for Windows was used for statistical evaluation (SPSS Inc., Chicago, IL, USA). A statistically significant difference was accepted when the value was lower than 0.05 . 
TABLE 3: Change in symptom scores obtained after treatment with Tadalafil $5 \mathrm{mg}$ daily for six months. DOMAIN 1: voiding disorders, DOMAIN 2: spontaneous and/or ejaculatory pain or discomfort; DOMAIN 3: sexual disorders; DOMAIN 4: quality of life.

\begin{tabular}{lccc}
\hline & P & PV & PVE \\
\hline DOMAIN 1 (T0) & $10.0 \pm 3.0$ & $13.0 \pm 2.0$ & $17.0 \pm 1.0^{\wedge}$ \\
DOMAIN 1 (T1) & $5.0 \pm 1.0^{*}$ & $7.0 \pm 2.0^{*}$ & $7.0 \pm 2.0^{*}$ \\
\hline DOMAIN 2 (T0) & $12.0 \pm 3.0$ & $18.0 \pm 2.0$ & $22.0 \pm 2.0^{\wedge}$ \\
DOMAIN 2 (T1) & $7.0 \pm 2.0^{*}$ & $10.0 \pm 2.0^{*}$ & $12.0 \pm 2.0^{*}$ \\
\hline DOMAIN 3 (T0) & $10.0 \pm 3.0$ & $16.0 \pm 2.0$ & $26.0 \pm 4.0^{\wedge}$ \\
DOMAIN 3 (T1) & $4.0 \pm 2.0^{*}$ & $8.0 \pm 2.0^{*}$ & $11.0 \pm 4.0^{*}$ \\
\hline DOMAIN 4 (T0) & $7.0 \pm 3.0$ & $10.0 \pm 2.0$ & $14.0 \pm 1.0^{\wedge}$ \\
DOMAIN 4 (T1) & $3.0 \pm 2.0^{*}$ & $5.0 \pm 2.0^{*}$ & $6.0 \pm 2.0^{*}$ \\
\hline
\end{tabular}

${ }^{*} p<0.001$ versus $\mathrm{T} 0 ; \wedge p<0.05$ versus $\mathrm{P}$ and $\mathrm{PV}$.

\section{Results}

At baseline, according to the ultrasound criteria, sixty-eight patients had uncomplicated MAGI and the other fifty-two patients had complicated MAGI (thirty patients with PV and twenty-two patients with PVE). The mean value of the scores obtained with IIEF-5 was $14.0 \pm 2.0$. After therapy, a significant increase in the mean value of IEEF-5 score (23.0 \pm 2.0 versus $14.0 \pm 2.0$ ) has been obtained.

After treatment, all domains of the SI-MAGI questionnaire were significantly improved in both groups (Table 3 ) and the percentage of spermatozoa with total and progressive motility was significantly improved in patients with PVE (Table 4). Finally, after treatment, according to the ultrasound criteria, ninety patients had uncomplicated MAGI $(+32 \%)$ and another thirty patients $(-42 \%)$ had complicated MAGI (twenty patients with PV and ten patients with PVE) (Table 5).

Other aspects of sexual function, different from erection quality, were significantly improved after pharmacological treatment (Table 5). In particular, the improvement is represented by the reduction of the percentage of patients who reported these symptoms evaluated through the SI-MAGI questionnaire (Table 6).

\section{Discussion}

The results of our study show that pharmacological treatment with Tadalafil $5 \mathrm{mg}$ daily for six months, in selected patients with amicrobic MAGI and DE (not due to endocrine or vascular causes), is associated with significant improvements in sexual function, sperm parameters, and quality of symptoms reported by patients. In particular, the improvement of sexual function was assessed through the IIEF-5 questionnaire score that was significantly improved after treatment. Regarding the sperm parameters in patients with PVE (generally associated with lower quality of semen), there was a significant increase of sperm motility. Finally, with regard to other symptoms, the use of a specific questionnaire for these patients (SI-MAGI) allows to evaluate improvements relating to other sexual domains different from the isolated DE, such as urinary disorders, chronic
TABLE 4: Main sperm parameters examined before and after pharmacological treatment with Tadalafil $5 \mathrm{mg}$ daily for six months.

\begin{tabular}{lccc}
\hline & $\mathrm{P}$ & $\mathrm{PV}$ & PVE \\
\hline Volume (T0) ml & $2.2 \pm 1.1$ & $1.9 \pm 1.1$ & $1.8 \pm 1.0$ \\
Volume (T1) ml & $2.4 \pm 1.2$ & $2.1 \pm 1.2$ & $2.0 \pm 1.2$ \\
\hline Density (T0) $\mathrm{mil} / \mathrm{ml}$ & $33.0 \pm 8.0$ & $26.0 \pm 8.0$ & $18.0 \pm 8.0$ \\
Density (T1) mil/ml & $36.0 \pm 6.0$ & $29.0 \pm 9.0$ & $24.0 \pm 7.0$ \\
\hline Normal forms (T0) \% & $10.0 \pm 4.0$ & $9.0 \pm 3.0$ & $9.0 \pm 4.0$ \\
Normal forms (T1) \% & $12.0 \pm 6.0$ & $10.0 \pm 4.0$ & $10.0 \pm 3.0$ \\
\hline Total motility (T0) \% & $32.0 \pm 9.0$ & $30.0 \pm 8.0$ & $16.0 \pm 8.0$ \\
Total motility (T1) \% & $36.0 \pm 7.0$ & $33.0 \pm 6.0$ & $30.0 \pm 6.0^{*}$ \\
\hline Prog. motility (T0) \% & $25.0 \pm 5.0$ & $24.0 \pm 8.0$ & $10.0 \pm 8.0$ \\
Prog. motility (T1) \% & $28.0 \pm 4.0$ & $26.0 \pm 6.0$ & $25.0 \pm 6.0^{*}$ \\
\hline Leukocytes (T0) mil/ml & $1.2 \pm 0.6$ & $1.4 \pm 0.4$ & $1.5 \pm 0.6$ \\
Leukocytes (T1) mil/ml & $1.0 \pm 0.3$ & $1.1 \pm 0.3$ & $1.2 \pm 0.4$ \\
\hline
\end{tabular}

${ }^{*} p<0.001$ versus T0.

TABLE 5: Redistribution of categories of MAGI (P: prostatitis; PV: prostate-vesiculitis; PVE: prostate-vesciculo-epididymitis) evaluated according to ultrasound criteria before and after treatment with Tadalafil $5 \mathrm{mg}$ daily for six months.

\begin{tabular}{lccc}
\hline & P & PV & PVE \\
\hline Baseline & 68 & 30 & 22 \\
After treatment & $90^{*}$ & $20^{*}$ & $10^{*}$ \\
\hline
\end{tabular}

${ }^{*} p<0.001$ versus T0.

pelvic pain, and quality of life. With regard to sexual dysfunction, the questions contained in this questionnaire evaluate aspects such as libido and quality of ejaculation, which also had improved results.

Pharmacological treatment of patients with uncomplicated inflammatory MAGI is controversial. The literature has reported several pharmacological approaches with antibiotics (even with prostatic injections), alpha lithic, prostatic massage, and so on, but none of them found wide consensus in clinical practice [8]. The rationale for the use of phosphodiesterase $\mathrm{V}$ selective inhibitors in these patients could be attributed to possible relaxation of the prostatic smooth muscle and consequently, the increase of the prostatic tissue's ability to eliminate more rapidly the intraprostatic reflux products [8]. In clinical practice, the use of sildenafil (first molecule for this class) has been reported to determine the improvement of urinary symptom scores [9]. The enzyme NOS (nitric oxide synthase) is expressed in the transitional and peripheral regions of the prostate tissue, as shown by immunohistochemical studies [10]. In vitro, the localization of NOS within the prostatic smooth muscle has been reported [11]. Many years ago, it was suggested that the intraprostatic urinary reflux in the periurethral and transitional regions of the prostate represents a key dysfunctional element, responsible for the chronicity of the inflammatory process, which can also involve the peripheral zone of the gland [12]. Kirby et al. (the same first author 30 years after) reported the clinical case of a patient suffering from 
TABle 6: Percentage of the improvement reported to question numbers 1, 4, 5, 6, and 8 of the domain regarding sexual function assessed through the SI-MAGI questionnaire.

\begin{tabular}{lccr}
\hline & Item & Baseline & After treatment \\
\hline 1 & Reduction of libido & $30 / 120(25.00 \%)$ & $12 / 120(10.00 \%)^{*}$ \\
4 & Difficulties in the second report & $60 / 120(50.00 \%)$ & $30 / 120(25.00 \%)^{*}$ \\
5 & Premature ejaculation & $10 / 120(8.00 \%)$ & $5 / 120(4.00 \%)^{*}$ \\
6 & Delayed ejaculation & $15 / 120(12.50 \%)$ & $10 / 120(8.00 \%)^{*}$ \\
8 & Painful ejaculation & $12 / 120(10.00 \%)$ & $5 / 120(4.00 \%)^{*}$ \\
\hline
\end{tabular}

${ }^{*} p<0.001$ versus T0.

prostatodynia, controlled for 7 years with the use of morphine, intolerant to NSAIDs, and with complete resolution of symptoms after a period of treatment with Tadalafil $10 \mathrm{mg}$ and $20 \mathrm{mg}$. After withdrawal of treatment, the patient reported reappearance of the same symptoms, so the patient was restarted treatment with Tadalafil $5 \mathrm{mg}$ daily with new resolution of the symptoms. The authors report to have prescribed the same therapy in their clinical experience with the other patients with the same clinical features, with the same results [13]. In another clinical experience (a randomized, open-label, three-arm study), Liguori and colleagues evaluated the efficacy of a combined therapy with an alpha1-blockers (alfuzosin) and Tadalafil in 66 patients with lower urinary tract symptoms and ED. Results of this study showed that improvement in the maximum urinary flow rate was observed in all groups, but patients receiving combination therapy had greater improvement $(29.6 \%)$ compared to patients treated only with alfuzosin $(21.7 \%)$ or only Tadalafil (9.5\%). Finally, the International Prostatic Symptom Score was significantly improved in patients treated with alfuzosin (27.2\%) and was more marked with the combination therapy (41.6\%), and a small increase, although not significant, was also observed on patients treated with Tadalafil (8.4\%) [14].

Relative to the effects on spermatogenesis, the effectiveness of Tadalafil is very controversial. In the experimental model, it has been documented that rats exposed to increasing doses for 12 weeks (equivalent of 5, 10, and $20 \mathrm{mg}$ daily) showed worsening of sperm parameters and a dosedependent histopathological degenerative change of the seminiferous tubules and also in Johnsen's score (qualitative evaluation of spermatogenesis) was significantly lower in the animal treated with a dose of $1.8 \mathrm{mg} / \mathrm{kg}$ (equivalent to $20 \mathrm{mg}$ ) [15].

In a previous study, the acute administration of Tadalafil $20 \mathrm{mg}$, compared with the acute administration of sildenafil $50 \mathrm{mg}$, determined different effects on the percentage of spermatozoa with progressive motility. In particular, 1 and 2 hours after the administration of sildenafil, the authors observed a significant improvement in the progressive motility; on the contrary, after administration of Tadalafil, a significant reduction of the same parameter was observed [16]. The results of our study are not comparable for different reasons: different doses used $(5 \mathrm{mg}$ versus $20 \mathrm{mg}$ ), duration of the treatment (six months versus acute administration), and different clinical model (in our study, we enrolled patients with MAGI). In pathophysiological terms, the different modulations of sperm motility obtained 1 and 2 hours after administration suggest a pharmacological mechanism that could involve the secretion of prostate and seminal vesicles and not the epididymal phase of maturation [15]. Moreover, it should also be considered that Tadalafil in the therapeutic range plays also an inhibitory role on isoenzyme 11, involved in the modulation of spermatogenesis [17]. However, from a clinical point of view, the study of Hellstrom et al. showed that chronic daily use of Tadalafil 10 or $20 \mathrm{mg}$ versus placebo was not associated with alterations of the sperm parameters [18]. Moreover, a recent Italian study conducted on 27 men aged between 19 and 35 years, suffering from psychogenic $\mathrm{ED}$, and unaware of their fertility condition showed that after pharmacological treatment with Tadalafil $5 \mathrm{mg}$ daily for 12 weeks, there was a significant improvement of sperm motility and their ejaculate volume [19]. Our results demonstrate that after treatment, only patients with PVE had a significant improvement in the progressive sperm motility. It is known that PVE represents the category with the lower quality of sperm parameters; moreover, it was demonstrated that the inflammatory dysfunction of the seminal vesicles contributes to further reduction of sperm motility, through different mechanisms, including the reduction of seminal concentrations of fructose [20]. In our previous study, we reported that after pharmacological treatment with Tadalafil, the ejection fraction of the seminal vesicles were significantly increased, suggesting a possible decontracting action of the treatment [21]. Moreover, the ultrasound evaluation allows to discriminate an "hypertrophic congestive" variant characterized by the dilation of the seminal vesicles $(>14 \mathrm{~mm})$ that represent the category with higher response to pharmacological treatment, other than the ultrasound variant called "fibro-sclerotic" associated with persistent low sperm quality after pharmacological treatment [22].

Another important aspect of the study concerns the possible improvements achieved by patients treated with Tadalafil regarding other sexual aspects, such as ejaculatory function and increased of libido. About the first aspect, in the literature, there is a growing interest and convergence for the possible use of Tadalafil in ejaculation disorders. In particular, the recent study by Ozcan et al. examined the intravaginal ejaculatory latency times (IELTs) of 30 men with lifelong premature ejaculation, treated for a month with Tadalafil $5 \mathrm{mg}$, showing a significant improvement in IELTs and plasma concentrations of nitric oxide after treatment [23]. Previously, Paduch et al. examined the ejaculatory and orgasmic function of 
Tadalafil $5 \mathrm{mg} /$ daily in patients with MAGI: possible advantages

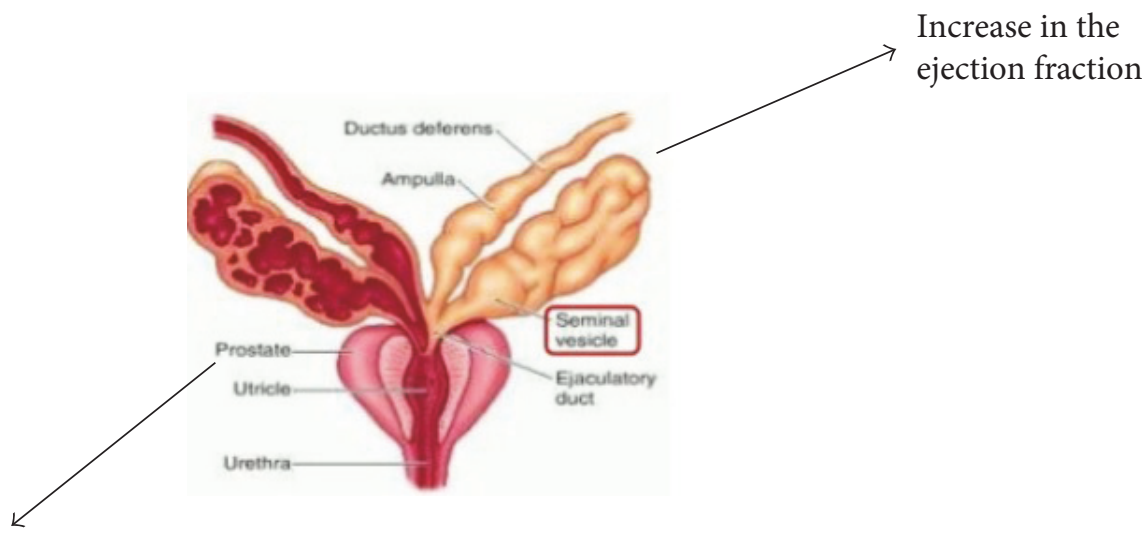

Decrease of the intraprostatic urinary reflux

Parameter

Improvement of sperm progressive motility

Improvement of erectile function

Improvement of other aspects of male sexuality

Reduction of other dysfunctional symptoms
Evaluation tool

WHO 2010

IIEF-5

SI-MAGI

SI-MAGI

FIGURE 1: Tadalafil $5 \mathrm{mg} /$ daily in patients with MAGI: possible advantages.

patients with ED treated with Tadalafil. The authors evaluated 17 placebo-controlled trials lasting 12 weeks with the administration of Tadalafil at different doses $(5,10$, and $20 \mathrm{mg})$, for a total of 2581 subjects. The study showed that Tadalafil 10 and $20 \mathrm{mg}$ were associated with improvement of ejaculatory and orgasmic function in these patients [24]. Regarding the reduced percentage of patients who report painful ejaculation after therapy, there are no other clinical studies in the literature that examined the usefulness of treatment with Tadalafil. However, it is important to consider that the $\mathrm{P}$ is associated with painful ejaculation [25] and therefore, the overall improvement in symptoms could also lead this change. Actually, the main therapeutic option for the treatment of painful ejaculation is represented by alpha-lytic treatment [26]. Finally, the possible increase in serum testosterone levels' (aspect not evaluated in our study) consequence of increased sexual activity [27] or a direct and/or indirect action favored by the administration of Tadalafil [27] could justify the reduced percentage of patients with reduced libido and delayed ejaculation [28] after the treatment.

In our study, after treatment, through ultrasound evaluation, we observed an increase in the percentage of patients with uncomplicated MAGI and a reduction in the percentage of patients with complicated MAGI (P and PV). There are no other studies in the literature that have evaluated this specific aspect, which, however, assumes a particular importance, since it suggests the potential use of Tadalafil $5 \mathrm{mg}$ daily for the secondary prevention of the chronicity of the inflammatory process and the possible complication of $\mathrm{P}$ in $\mathrm{PV}$ and/ or PVE that are the categories with higher severity of signs and symptoms [4].

In conclusion, the results of this study suggest that therapy with Tadalafil $5 \mathrm{mg}$ daily in patients with MAGI improves sexual function, sperm quality, and severity of symptoms and may prevent progression into complicated forms. The two main mechanisms that literature suggests to explain these effects could be the reduction of intraprostatic reflux [12] and the increased drainage of the seminal vesicles [21]. The absence of a control group is the main limitation of the study. Subsequent studies will have to confirm maintenance of the long-term effects. Figure 1 summarizes the possible advantages of the treatment with Tadalafil $5 \mathrm{mg}$ in patients with MAGI.

\section{Conflicts of Interest}

The authors declare that there is no conflict of interest regarding the publication of this paper.

\section{References}

[1] F. Comhaire, G. Verschraegen, and L. Vermeulen, "Diagnosis of accessory gland infection and its possible role in male infertility," International Journal of Andrology, vol. 3, no. 1, pp. 32-45, 1980.

[2] K. Everaert, A. Mahmoud, C. Depuydt, M. Maeyaert, and F. Comhaire, "Chronic prostatitis and male accessory gland 
infection-is there an impact on male infertility (diagnosis and therapy)?" Andrologia, vol. 35, no. 5, pp. 325-330, 2003.

[3] S. La Vignera, R. A. Condorelli, E. Vicari, V. Favilla, G. Morgia, and A. E. Calogero, "Acquired premature ejaculation and male accessory gland infection: relevance of ultrasound examination," Asian Journal of Andrology, vol. 18, no. 5, pp. 769-772, 2016.

[4] S. La Vignera, "Male accessory gland infections: anatomical extension of inflammation and severity of symptoms evaluated by an original questionnaire," Andrologia, vol. 44, Supplement 1, pp. 739-746, 2012.

[5] S. La Vignera, A. E. Calogero, R. A. Condorelli et al., "Ultrasonographic evaluation of patients with male accessory gland infection," Andrologia, vol. 44, Supplement 1, pp. 26-31, 2012.

[6] R. C. Rosen, J. C. Cappelleri, M. D. Smith, J. Lipsky, and B. M. Peña, "Development and evaluation of an abridged, 5 -item version of the International Index of Erectile Function (IIEF-5) as a diagnostic tool for erectile dysfunction," International Journal of Impotence Research, vol. 11, no. 6, pp. 319-326, 1999.

[7] World Health Organization, WHO Laboratory Manual for the Examination and Processing of Human Semen, Cambridge University Press, Cambridge, UK, 2010.

[8] S. J. Grimsley, M. H. Khan, and G. E. Jones, "Mechanism of phosphodiesterase 5 inhibitor relief of prostatitis symptoms," Medical Hypotheses, vol. 69, no. 1, pp. 25-26, 2007.

[9] K. Sairam, E. Kulinskaya, T. A. McNicholas, G. B. Boustead, and D. C. Hanbury, "Sildenafil influences lower urinary tract symptoms," BJU International, vol. 90, no. 9, pp. 836-839, 2002.

[10] A. L. Burnett, M. P. Maguire, S. L. Chamness et al., "Characterization and localization of nitric oxide synthase in the human prostate," Urology, vol. 45, no. 3, pp. 435-439, 1995.

[11] M. Takeda, R. Tang, E. Shapiro, A. L. Burnett, and H. Lepor, "Effects of nitric oxide on human and canine prostates," Urology, vol. 45, no. 3, pp. 440-446, 1995.

[12] R. S. Kirby, D. Lowe, M. I. Bultitude, and K. E. Shuttleworth, "Intra-prostatic urinary reflux: an aetiological factor in abacterial prostatitis," British Journal of Urology, vol. 54, no. 6, pp. 729-731, 1982.

[13] R. S. Kirby, C. Carson 3rd, and P. Dasgupta, "Daily phosphodiesterase type 5 inhibitor therapy: a new treatment option for prostatitis/prostatodynia?" BJU International, vol. 113, no. 5, pp. 694-695, 2014.

[14] G. Liguori, C. Trombetta, G. De Giorgi et al., "Efficacy and safety of combined oral therapy with tadalafil and alfuzosin: an integrated approach to the management of patients with lower urinary tract symptoms and erectile dysfunction. Preliminary report," The Journal of Sexual Medicine, vol. 6, no. 2, pp. 544-552, 2009.

[15] A. A. Eid, F. M. Badr El Dine, and I. M. Nabil, "Histopathologic and ultrastructural changes in seminiferous tubules of adult male albino rats following daily administration of different doses of tadalafil," Urology, vol. 90, pp. 89-96, 2016.

[16] G. Pomara, G. Morelli, D. Canale et al., "Alterations in sperm motility after acute oral administration of sildenafil or tadalafil in young, infertile men," Fertility and Sterility, vol. 88 , no. 4 , pp. 860-865, 2007.

[17] C. Wayman, S. Phillips, C. Lunny et al., "Phosphodiesterase 11 (PDE11) regulation of spermatozoa physiology," International Journal of Impotence Research, vol. 17, no. 3, pp. 216-223, 2005.
[18] W. J. Hellstrom, J. W. Overstreet, A. Yu et al., "Tadalafil has no detrimental effect on human spermatogenesis or reproductive hormones," The Journal of Urology, vol. 170, no. 3, pp. 887891, 2003.

[19] A. Corvasce, G. Albino, T. Leonetti, A. F. Buonomo, and E. C. Marucco, "Once-a-day tadalafil administration improves the spermogram parameters in fertile patients," Archivio Italiano di Urologia, Andrologia, vol. 87, no. 3, pp. 210-213, 2015.

[20] E. Vicari, S. La Vignera, R. Castiglione, and A. E. Calogero, "Sperm parameter abnormalities, low seminal fructose and reactive oxygen species overproduction do not discriminate patients with unilateral or bilateral post-infectious inflammatory prostato-vesiculo-epididymitis," Journal of Endocrinological Investigation, vol. 29, no. 1, pp. 18-25, 2006.

[21] S. La Vignera, "Seminal vesicles of infertile patients with male accessory gland infection: ultrasound evaluation after prolonged treatment with tadalafil, a selective phosphodiesterase5 inhibitor," Andrologia, vol. 45, no. 6, pp. 386-391, 2013.

[22] S. La Vignera, E. Vicari, R. Condorelli, R. D'Agata, and A. E. Calogero, "Hypertrophic-congestive and fibro-sclerotic ultrasound variants of male accessory gland infection have different sperm output," Journal of Endocrinological Investigation, vol. 34, no. 10, pp. e330-e335, 2011.

[23] L. Ozcan, E. C. Polat, E. Onen et al., "Effects of tadalafil $5 \mathrm{mg}$ dosed once daily in men with premature ejaculation," Urologia Internationalis, vol. 98, no. 2, pp. 210-214, 2017.

[24] D. A. Paduch, A. Bolyakov, P. K. Polzer, and S. D. Watts, "Effects of 12 weeks of tadalafil treatment on ejaculatory and orgasmic dysfunction and sexual satisfaction in patients with mild to severe erectile dysfunction: integrated analysis of 17 placebo-controlled studies," BJU International, vol. 111, no. 2, pp. 334-343, 2013.

[25] C. P. Ilie, D. L. Mischianu, and R. J. Pemberton, "Painful ejaculation," BJU International, vol. 99, no. 6, pp. 1335-1339, 2007.

[26] D. Delavierre, L. Sibert, J. Rigaud, and J. J. Labat, "Painful ejaculation," Progrès en Urologie, vol. 24, no. 7, pp. 414-420, 2014.

[27] R. Knussmann, K. Christiansen, and C. Couwenbergs, "Relations between sex hormone levels and sexual behavior in men," Archives of Sexual Behavior, vol. 15, no. 5, pp. 429-445, 1986.

[28] E. Carosa, P. Martini, F. Brandetti et al., "Type V phosphodiesterase inhibitor treatments for erectile dysfunction increase testosterone levels," Clinical Endocrinology, vol. 61, no. 3, pp. 382-386, 2004. 


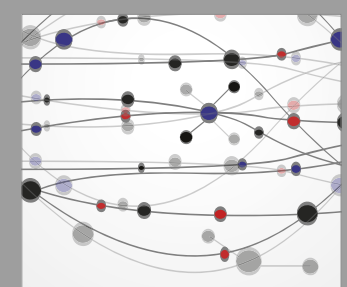

The Scientific World Journal
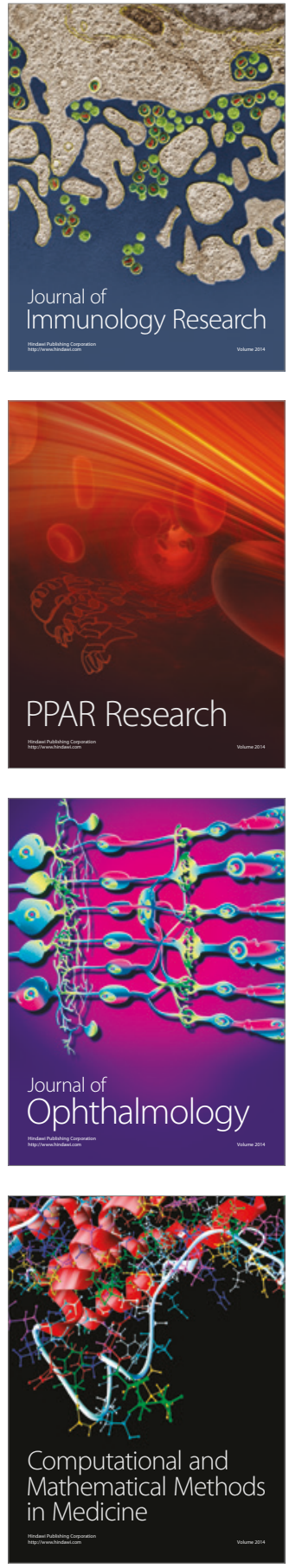

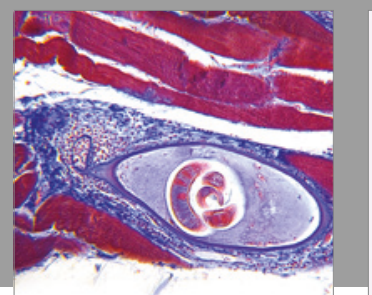

Gastroenterology Research and Practice
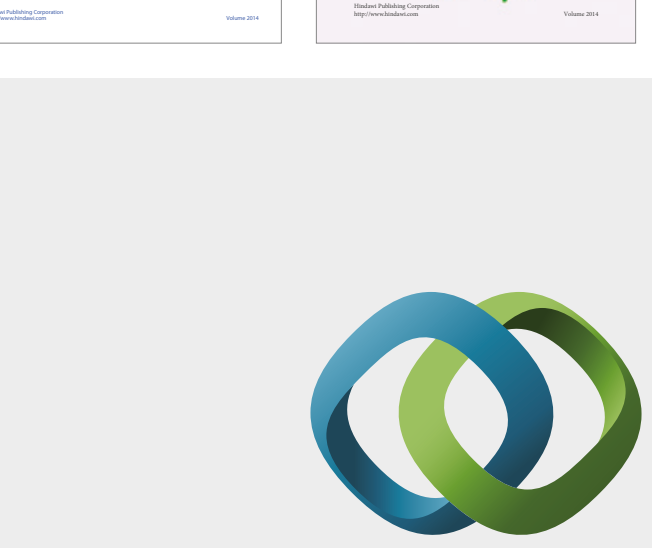

\section{Hindawi}

Submit your manuscripts at

https://www.hindawi.com
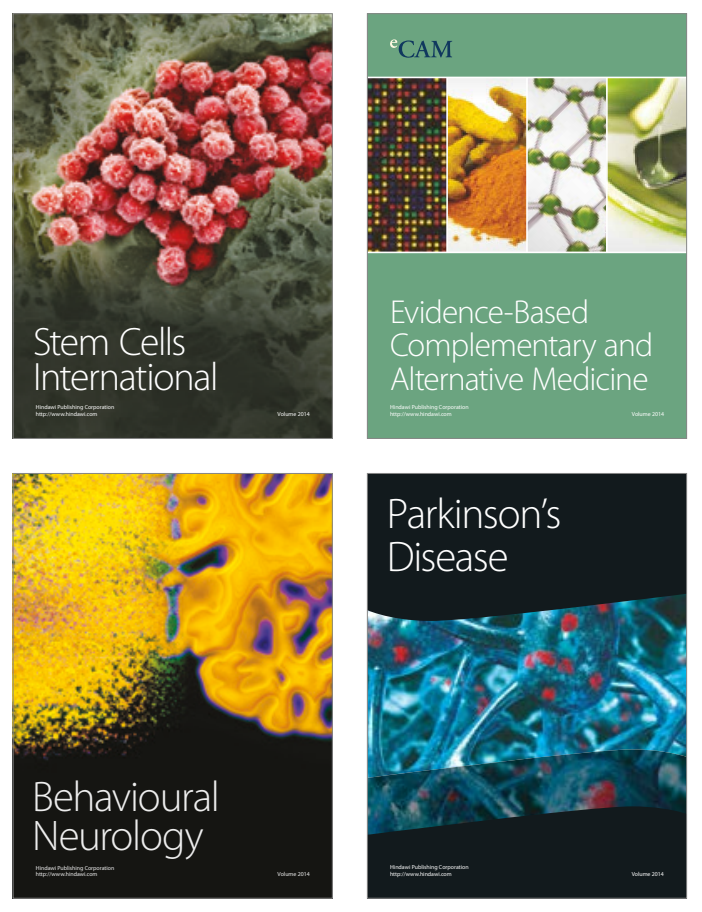
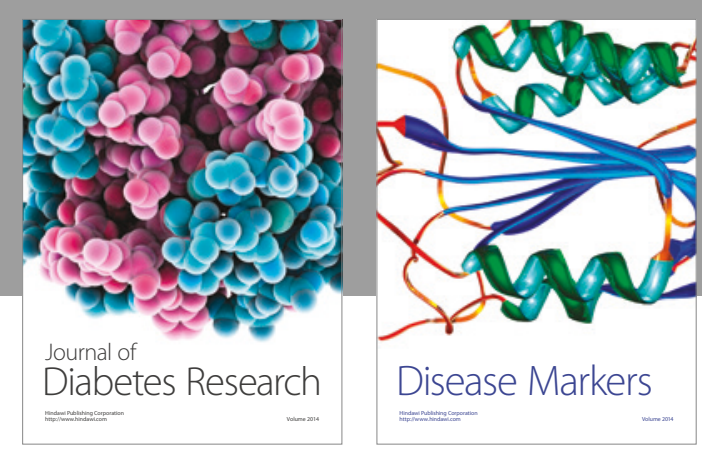

Disease Markers
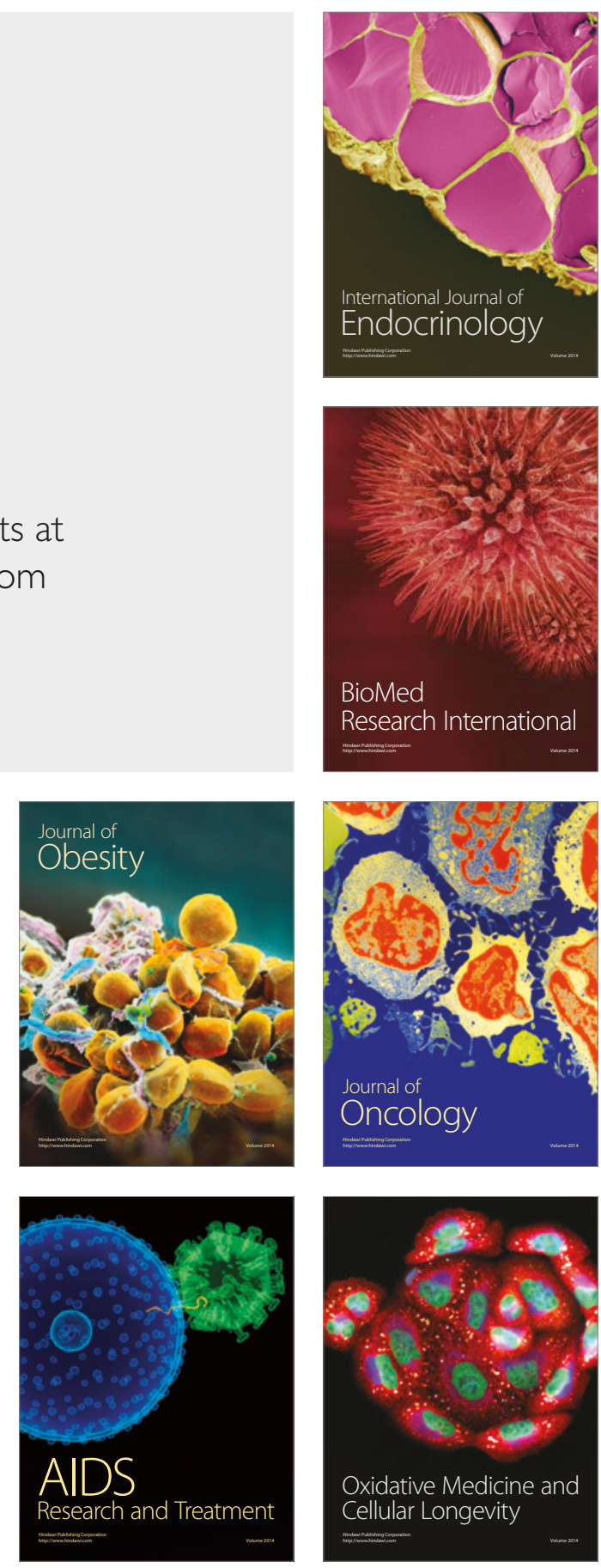